\title{
IMPLEMENTASI E-COMMERCE DENGAN CONTENT MANAGEMENT SYSTEM WORDPRESS MENGGUNAKAN WOOCOMMERCE PADA HOPEANDSOLES.ID
}

\author{
Andika Fauzan Pratama ${ }^{1}$, Anita Diana ${ }^{2 *}$ \\ ${ }^{1,2}$ Fakultas Teknologi Informasi, Sistem Informasi, Universitas Budi Luhur, Jakarta, Indonesia \\ Email: ${ }^{1}$ Andikafauzanp@email.com, ${ }^{2 *}$ anita.diana@ budiluhur.ac.id
}

\begin{abstract}
Abstrak -Studi kasus dalam penelitian ini adalah pada toko yang bergerak dibidang penjualan sepatu. Saat ini proses penjualannya masih memanfaatkan fitur aplikasi chat sebagai media penjualan. Beberapa masalah yang terjadi diantaranya media pemasaran kurang efektif sehingga pemasaran produk kurang luas, terjadi kesalahan dalam pesanan karena masih dilakukan secara manual, penjualan kurang maksimal karena hanya di media sosial, informasi laporan yang dibutuhkan kurang informatif. Oleh karena itu toko sepatu ini membutuhkan sebuah bisnis E-Commerce melalui website untuk mengatasi permasalahannya. Website E-commerce yang dibangun berbasis content management system (CMS) dengan aplikasi Wordpress, karena CMS dapat membuat, mengatur, mendistribusikan, mempublikasi dan menjaga sebuah informasi suatu perusahaan atau institusi, tanpa harus menguasai tag HTML untuk mengaplikasikannya. Dan salah satu aplikasi CMS adalah Wordpress yang mudah digunakan. Dengan bisnis e-commerce yang dibuat melalui website ini, pemasaran produk lebih efektif, pelanggan mudah bertransaksi secara online, data pesanan tersimpan baik, penjualan akan lebih maksimal, dan informasi laporan menjadi lebih informatif.
\end{abstract}

Kata Kunci : usaha sepatu, e-commerce, CMS, Wordpress.

Abstract-The case study in this research is on a shop engaged in the sale of shoes. Currently the sales process is still using the chat application feature as a sales medium. Some of the problems that occur include ineffective marketing media so that product marketing is less extensive, errors occur in orders because it is still done manually, sales are not optimal because only on social media, the required report information is less informative. Therefore this shoe shop needs an E-Commerce business through a website to solve the problem. E-commerce websites that are built based on content management system (CMS) with Wordpress applications, because CMS can create, organize, distribute, publish and maintain information on a company or institution, without having to master HTML tags to apply it. And one of the CMS applications is WordPress which is easy to use. With the e-commerce business created through this website, product marketing is more effective, customers can easily transact online, order data is stored well, sales will be maximized, and report information becomes more informative.

Keyword: shoe sales, e-commerce, CMS, Wordpress.

\section{PENDAhuluan}

Perkembangan bisnis di era yang hampir semuanya serba digital memiliki peningkatan yang cukup pesat diantaranya bisnis mode, makanan maupun tempat kopi. Pemilik harus melakukan sebuah peningkatan pelayanan demi menjaga kelangsungan bisnis. Begitu juga dengan penjualan sepatu yang dilakukan secara daring, karena saat ini penjualan sepatu menjadi suatu usaha yang sedang meningkat. Banyak orang yang memulai bisnis jasa jual sepatu. Untuk mencari sebuah konsumen pelaku usaha biasanya menggunakan alat bantu pencari untuk menemukan informasi terkait hal yang sedang dicari. Saat ini penjualan sepatu memasarkan produk mereka melalui sosial media. Hal ini dilakukan, karena pelaku usaha penjual sepatu, belum memiliki website yang mendukung penjualan dan pemesanan secara otomatis sebagai medium pendukung lainnya selain sosial media yang dimiliki. Sehingga para pelaku usaha, belum dapat mengelola penjualan dengan optimal. Oleh karena itu masih terjadi kemungkinan kesalahan dalam pencatatan transaksi penjualan dan pencatatan data pesanan pelanggan.

Hopeandsoles.id merupakan sebuah usaha di bidang mode yang berdiri sejak tahun 2018 dengan usaha sebagai distributor sepatu Vans dengan metode pembayaran Cash On Delivery dan bank transfer. Proses pemasaran yang terjadi pada hopeandsoles.id cukup baik dengan menggunakan media sosial Instagram sebagai media pemasarannya. Saat ini Hopeandsoles.id memanfaatkan fitur aplikasi Whatsapp sebagai media sarana komunikasi dengan pelanggan sehingga pelanggan tidak bisa melakukan pemesanan secara langsung. Dengan belum adanya proses pendataan pesanan, Hopeandsoles.id akan sulit mengembangkan usahanya karena tidak memiliki data yang dapat diolah kembali untuk menjadi infromasi yang berguna seperti pengembangan ide pemasaran atau perluasan target pasar.

Menurut Kosasi [1] Sistem informasi penjualan berbasis web memiliki fitur navigasi yang memberikan kemudahan bagi pengunjung dalam hal ini baik konsumen ataupun pelanggan saat mengunjungi halaman situs web. Memiliki kontribusi untuk menyelesaikan persoalan dalam bentuk jaminan layanan informasi yang lebih 
dekat kepada konsumen dan bermigrasi ke proses penjualan yang didigitalisasi. Menampilkan pesan-pesan tertentu dan mengarahkan pengunjung, calon pembeli untuk dapat melakukan proses pemesanan barang secara daring kapan dan dimanapun serta mendapatkan informasi produk secara cepat.

Penelitian ini disusun karena terdapat masalah yang terjadi pada hopeandsoles.id. Diantaranya adalah media pemasaran yang dijalankan saat ini kurang efektif sehingga cakupan pemasaran produk dirasakan kurang luas untuk diketahui dan dikenali oleh masyarakat. Lalu masih kurangnya akses informasi yang didapat oleh pelanggan sehingga pelanggan kurang percaya untuk melakukan transaksi, terjadi kesalahan dalam mengelola pesanan karena pencatatan data masih dilakukan secara manual yaitu lewat kertas dan buku. Selain itu proses penjualan hanya terjadi di media sosial (Instagram \& Whatsapp), sehingga penjualan belum maksimal. Dan usaha sepatu ini belum memiliki laporan produk, laporan pengiriman, laporan pembayaran, laporan pesanan, laporan pelanggan yang dibutuhkan oleh pemilik toko, sehingga informasi laporan yang dibutuhkan kurang informatif.

Penelitian ini bertujuan untuk memaksimalkan pemasaran produk sehingga pemasaran menjadi efektif, untuk memudahkan pelanggan untuk bertransaksi secara online, dan menambah pelayanan hopeandsoles.id menjadi lebih baik dan informatif. Tujuan lainnya adalah dengan adanya website ecommerce, pencatatan dengan pesanan tidak dilakukan secara manual dan dapat tersimpan dengan baik pada database. Selain itu dengan dengan adanya fitur-fitur yang mendukung untuk melakukan penjualan dan website sudah teroptimasi, maka penjualan akan lebih maksimal. Dengan adanya website akan menghasilkan laporan Rekapitulasi Produk Terlaris, laporan Pengiriman, laporan Pembayaran, laporan Pesanan, laporan Pelanggan dan laporan pendapatan yang dibutuhkan oleh pemilik toko, sehingga informasi yang dibutuhkan efektif dan informatif.

Pada penelitian sebelumnya [2] membahas implementasi e-commerce dengan berbasis content management system pada toko sepokatsepatu. Penelitian ini menggunakan CMS wordpress dan woocommerce, mengungkapkan bahwa dengan adanya website yang e-commerce dengan basis content management system di toko tersebut, dapat memudahkan penjualan dengan lebih luas. Dampak lain bagi pelanggan, adalah akan dengan mudah untuk mendapatkan informasi mengenai produk pada toko tersebut.

Pada penelitian lainnya [3] dikemukakan bahwa proses yang dilakukan oleh toko tersebut masih manual dan kurang optimal sebelum diterapkan aplikasi website. Setelah melakukan penerapan aplikasi yang berbasis content management system, pemasaran yang terdapat di toko alya gorden menjadi lebih maksimal sehingga dapat melakukan pemasaran yang lebih luas. Proses bisnis pada toko alya gorden pun dirasakan lebih mudah dan dapat memberikan kepuasan bagi pelanggan.

Pada penelitian lainnya pula [4] dikemukakan bahwa dengan menerapkan E-Commerce pada Sepatu Sneakers Bintaro dapat memudahkan customer dalam melakukan transaksi dimanapun dan kapanpun tanpa harus melakukan visit ke toko. Pemesanan bisa lebih mudah dan praktis dengan adanya penerapan E-Commerce sehingga customer dapat berperan secara aktif dalam proses jual-beli tanpa dibatasi waktu dan tempat. Dampak lainnya adalah mengatasi kesulitan dalam mempromosikan produk, dikarenakan pihak toko tidak memiliki media sosial atau marketplace sebagai wadah promosi produk. Pembuatan laporan pun dapat dipermudah dan dapat dipercepat karena adanya laporan yang dapat langsung di Export melalui WooCommerce Report, maka dari itu mencetak laporan dapat dilakukan dengan sigap dan akurat.

Toko sepatu hopeandsholes.id membutuhkan sebuah bisnis E-Commerce melalui website untuk mengatasi permasalahannya. Website E-commerce yang dibangun berbasis content management system (CMS) dengan aplikasi Wordpress, karena CMS dapat membuat, mengatur, mendistribusikan, mempublikasi dan menjaga sebuah informasi suatu perusahaan atau institusi, tanpa harus menguasai tag HTML untuk mengaplikasikannya. Dan salah satu aplikasi dari CMS adalah Wordpress yang mudah digunakan.

Menurut Rerung [5]E-commerce dapat didefinisikan sebagai arena terjadinya transaksi atau penukaran informasi baik antara penjual dan pembeli di dunia maya dan sebaliknya. E-commerce yang merupakan salah satu produk dari lahirnya teknologi informasi yang dapat dimanfaatkan untuk menciptakan daya saing khususnya dalam hal promosi dan menjual produk/jasa lintas daerah atau bahkan lintas negara sekalipun. Menurut Turban dkk [6] E-Commerce adalah sebuah model bisnis di mana proses transaksi dilakukan melalui jaringan elektronik atau internet. Kegiatan itu termasuk suatu proses pembelian dan penjualan barang, layanan, dan informasi secara daring. Jenis umum dari transaksi e-commerce, menurut Pradana [7] adalah B2B (Business to Business), B2C (Business to Consumer), C2C (Consumer to Consumer), C2B (Consumer to Business), B2G (Busines to Government) adalah turunan dari B2B, dan G2C (Government to Consumer). Konsumen, dalam hal ini masyarakat, dapat dengan mudah berhubungan pemerintah sehingga memperoleh kemudahan dalam pelayanan sehari-hari.

Menurut Elinawati, S. Dkk [3] Content Management System (CMS) merupakan sebuah sistem yang digunakan untuk mengelola proses pembuatan, pembaruan CMS dan publikasi konten secara seksama, yang menyangkut pada informasi dalam bentuk teks, grafik, gambar maupun dalam bentuk lainnya yang perlu dikelola terlebih dahulu. CMS dapat menciptakan, mengelola, menyalurkan, mempublikasi dan menjaga suatu informasi 
pada sebuah perusahaan atau instansi, tanpa harus menguasai tag HTML untuk menerapkannya. Salah satu aplikasi CMS adalah Wordpress yang mudah untuk diaplikasikan.

Content Management System (CMS) adalah sistem yang memenuhi serangkaian untuk persyaratan khusus dan dirancang untuk memanajemen konten. Menurut Vysotska [8] Content Management System juga digunakan untuk penyimpanan dan publikasi sejumlah dokumen, gambar, music dan video. Menurut Stern dkk [9] Wordpress merupakan sebuah Content Management System (CMS) yang open source paling populer yang tersedia, dengan pengguna, pengembang dan komunitas-komunitas dukungan global. Dalam desainnya, wordpress menggunakan beberapa plugins sehingga tampilannya menjadi lebih baik. WooCommerce adalah salah satu plugins wordpress yang sangat popular. Plugins ini membuat wordpress menjadi platform e-commerce yang baik. Suryono [10] mengemukakan Woocommerce merupakan plugin wordpress yang menjanjikan fasilitas toko daring yang powerfull dan juga elegan. Woocommerce memiliki fitur yang sangat banyak yang bertujuan untuk meningkatkan kinerja took daring semakin fungsinal, termasuk pada bagian dashboard untuk mengamati kemajuan bisnis. Oley dkk [11] mengemukakan bahwa WooCommerce memiliki banyak fitur untuk wordpress yang bertujuan untuk memudahkan penggunanya, maka WooCommerce dibentuk secara fleksibel.

Berdasarkan dengan adanya hal tersebut, maka kebutuhan untuk membuat website untuk hopeandsholes.id dirasa penting. Website e-commerce tersebut akan membuat pemasaran produk lebih efektif, pelanggan mudah bertransaksi secara online, data pesanan tersimpan baik, penjualan meningkat, dan menghasilkan informasi laporan menjadi lebih informatif. Hal ini dapat meningkatkan pemesanan dan usaha ini dapat berkembang serta bersaing.

\section{METODE PENELITIAN}

\subsection{Metode Pengumpulan Data}

Data yang dikumpulkan bertujuan untuk memperoleh informasi yang selanjutnya diolah agar mendapatkan tujuan penelitian. Penulis memiliki beberapa cara untuk mencari informasi yaitu sebagai berikut

a. Wawancara, teknik ini dilakukan dengan bertemu langsung kepada pemilik toko sepatu dengan mengajukan pertanyaan secara lisan untuk mendapatkan informasi mengenai toko sepatu tersebut.

b. Observasi, merupakan teknik pengumpulan data dengan survei secara langsung suatu kejadian yang terkait dengan peneltian. Penulis mengamati langsung di toko sepatu apa saja yang sudah berjalan sehingga dapat mengetahui penyelesaian masalah yang ada di toko sepatu.

c. Studi Literatur, merupakan teknik pengumpulan data dengan menganalisa berbagai artikel penelitian. Studi ini dilakukan dengan mencari dan mempelajari jurnal atau publikasi artikel ilmiah yang dapat dijadikan sebagai acuan pada kegiatan penelitian ini.

d. Analisa dokumen, adalah teknik pengumpulan data dengan mengumpulkan dokumen-dokumen yang ada pada toko sepatu.

Teknik analisa data yang memiliki manfaat untuk dapat memberikan kesimpulan dari hasil pengumpulan data menjadi suatu informasi yang mudah dipahami dan dimengerti, sehingga dapat menjawab masalah-masalah pada penelitian. Pada penelitian ini, teknik analisa data yang dilakukan adalah:

a. Analisa masalah, untuk mengetahui penyebab adanya masalah dengan melakukan observasi dan wawancara untuk merumuskan masalah dalam penelitian.

b. Analisa proses bisnis dilakukan suatu analisa proses bisnis untuk menjelaskan tentang proses bisnis pada toko sepatu serta identifikasi kebutuhan dengan metode UML.

\subsection{Tahap Perancangan Sistem}

Tahap perancangan sistem adalah merancang sistem dengan menggunakan UML berdasarkan hasil analisa terhadap sisem yang ada, sehingga menghasilkan model sistem baru yang diusulkan. Tools-tools yang digunakan dalam melakukan perancangan sistem yaitu $U M L$, antara lain class diagram, interaction modelling language, system sequence diagram, component diagram, dan rancangan layar. Menurut Nugroho [12], UML (Unified Modeling Language) merupakan bahasa pemodelan yang diperuntukan pada sistem atau perangkat lunak yang berparadigma 'berorientasi objek". Tujuan Penggunaan UML adalah:

a. Menunjukkan bahasa pemodelan yang tidak terikat dari berbagai bahasa pemrograman dan proses rekayasa.

b. Menggabungkan praktek-praktek terbaik yang terdapat dalam suatu pemodelan.

c. Memaparkan model bisnis yang siap pakai, bahasa pemodelan visual yang ekspresif untuk diekspansi dan saling menukar model dengan cara yang mudah dan dimengerti secara umum. 


\subsection{Tahap Perancangan Bisnis}

Penggunaan metode Bussiness Model Canvas dipilih untuk mempercepat proses analisis kekuatan dan kekurangan bisnis, karena dengan menggunakan Bussiness Model Canvas dapat mengetahui kekuatan dan kelemahan, maka analisis kebutuhan dan profit dapat dilakukan dengan cepat. Menurut Dinata dan Chumaidiyah [13], Business Model Canvas adalah suatu gambaran atau desain dari strategi bisnis yang mempresentasikan sembilan blok penting. Kesembilan blok tersebut saling merelasikan antara satu dengan yang lainnya untuk membentuk sebuah model bisnis. BMC merupakan sebuah alat yang dikembangkan oleh Alexander Osterwalder [14], yang digaungkan melalui bukunya Business Model Canvass. BMC dijabarkan untuk membantu organisasi pada lini bisnis dan pengusaha pemula untuk menempatkan dan melakukan analisa terhadap model bisnis mereka jalani. Dengan BMC yang digunakan sebagai tools, kita dapat memahami sebuah bisnis secara lebih besar dan luas. BMC dapat diandalkan sebagai alat analisis yang baik. Menurut Osterwalder [15], model ini digunakan untuk menjelaskan, memvisualisasikan atau menggambarkan, menilai, dan mengubah suatu model bisnis, agar mampu menghasilkan kinerja yang lebih optimal.

Business Model Canvas (BMC) memiliki 9 blok, yaitu Key Partners, Key Activites, Key Resources, Value Proposition, Customer Relationship, Channel, Customers Segments, Cost Structure, Revenue Streams. Menurut Osterwalder [15] Kesembilan blok yang disusun dalam BMC dituangkan dalam sebuah gambar yang terlihat Pada Gambar 1:

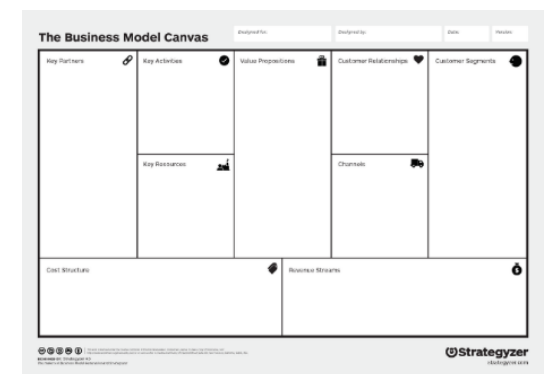

Gambar 1. Sembilan blok model bisnis [15]

Penelitian ini akan mengaplikasikan teknik Search Engine Optimization (SEO) untuk meningkatkan ranking pada mesin pencari. Biasanya terdapat langkah-langkah yang digunakan untuk menerapkan teknik SEO seperti halnya dengan menggunakan kata kunci yang sesuai dan telah diriset terlebih dahulu. Sehingga website dapat menampilkan pada halaman pertama mesin pencari ketika menggunakan kata kunci yang telah ditentukan. Menurut Diartono, Agus D, dkk [16] Optimisasi Mesin Pencari (Search Engine Optimization /SEO) merupakan rangkaian proses yang dilakukan secara sistematis yang bertujuan untuk meningkatkan volume dan kualitas ramailancarnya kunjungan suatu website melalui mesin pencari menuju situs website tertentu dengan memanfaatkan mekanisme kerja atau algoritma mesin pencari tersebut.

\section{HASIL DAN PEMBAHASAN}

\subsection{Kerangka Pemikiran}

Kerangka pemikiran berisi suatu teori dari pengumpulan data untuk memecahkan masalah. Kerangka pemikiran pada toko sepatu hopeandsoles.id dapat dilihat Pada Gambar 2. Kerangka pemikiran ini menggambarkan dari pengumpulan data perencanaan bisnis, tujuan hingga hasil yang telah di buat oleh penulis untuk memecahkan masalah pada toko sepatu hopeandsoles.id. Hasil dari e-commerce yang dibuat melalui website ini, antara lain pemasaran produk lebih efektif, pelanggan mudah bertransaksi secara online, data pesanan tersimpan baik, penjualan akan lebih maksimal, dan informasi laporan menjadi lebih informatif. 


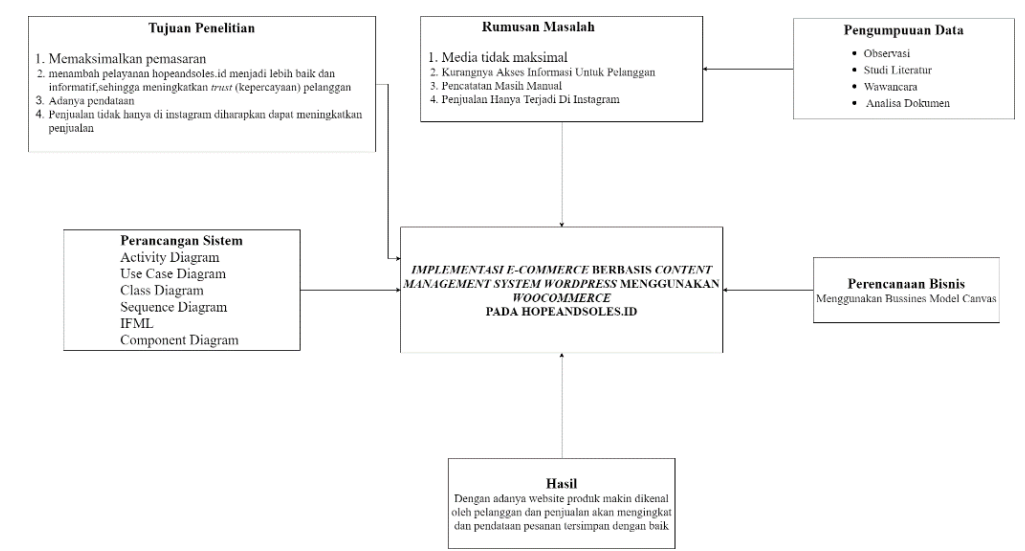

Gambar 2. Kerangka Pemikirian

\subsection{Business Model Canvas}

Strategi bisnis dituangkan dalam sebuah Business Model Canvas (BMC) yang mempunyai elemen-elemen didalamnya yang berfungsi untuk memvisualisasikan, menilai dan mengubah model bisnis pada toko sepatu. Berikut ini adalah strategi bisnis yang di tuangkan kedalam Business Model Canvas Pada Gambar 3.



Gambar 3. Business Model Canvas untuk toko sepatu

Dari Gambar 3 Business Model Canvas di toko sepatu hopeandsoles.id, maka kesembilan blok tersebut:

a. Key Partners: berlangsungnya usaha pasti membutuhkan pihak pihak yang lain untuk menunjang suatu usaha, toko sepatu bekerja sama dengan perusahaan logistic seperti JNE dan J\&T, lalu dengan adanya teknologi website hopeandsoles.id membayar sewa hosting dan domain agar website bekerja dengan baik.

b. Key Activites: aktivitas yang dijalankan untuk menjalankan bisnis dengan melakukan penjualan sepatu, pengemasan sepatu, pengiriman sepatu dan penjualan online melalui website. Setelah itu melakukan pemasaran guna untuk dikenal oleh masyarakat dengan lebih luas.

c. Value propositions: toko Hopeandsoles.id menjualkan sepatu original dengan harga murah dan pelanggan dapat menjadi resseler, terdapat layanan COD (Cash on Delivery) yang hanya didaerah ciputat dan bintaro.

d. Customer Relationship: dengan adanya customer relationship yang dijalankan hopeandsoles.id dapat mendatangkan konsumen baru dan mempertahankan konsumen lama. Dengan cara mengadakan diskon dan free ongkir untuk didaerah ciputat dan bintaro, lalu dengan adanya layanan konsultasi untuk menjadi resseler dapat menambahkan kepercayaan terhadap pelanggan.

e. Channels: setelah mendapatkan segmentasi pasar dibutuhkannya media sosial untuk menginformasikan suatu produk yang ada di hopeandsoles.id, dan dapat menjadi sarana pemesanan melalui aplikasi whatsapp, marketplace, dan website.

f. Customer Segments: sasaran customer hopeandsoles adalah para mahasiswa dan pelajar yang kesehariannya memakai sepatu saat beraktivitas, dan bagi seseorang yang ingin menjual kembali sepatu yang telah di beli sebagai reseller.

g. Cost Structure: pengeluaran atau beban biaya bagi hopeandsoles.id tersebut diantaranya biaya hosting, domain, internet, gaji staff, lalu adanya beban transportasi pengiriman barang yang menggunakan sepedah motor yang memerlukan bahan bakar.

h. Revenue Streams: pendapatan toko sepatu didapatkan dari penjualan sepatu di toko dan social media.

i. Key Resources: sumber daya yang menunjang untuk keperluan bisnis hopeandsoles.id adanya staff yang mengelola postingan Instagram hopeandsoles.id. Sebelum melakukan posting staff pun memerlukan 
smartphone untuk memfoto produk, lalu masuk ke tahap editing menggunakan laptop. Setelah itu staff memposting menggunakan smartphone ke dalam Instagram yang terkoneksi jaringan internet.

\subsection{Proses Bisnis Usulan}

Proses bisnis yang diusulkan dalam penjualan sepatu melalui website yang dibuat, terlihat dalam activity diagram. Triandini dan Suardika [17] mengemukakan bahwa Activity Diagram adalah sebuah diagram alur kerja yang menjelaskan berbagai kegiatan pengguna atau sistem. Berikut adalah proses bisnis usulan dan activity diagram untuk proses pemesanan, proses pembayaran, proses pengiriman dan proses pembuatan laporan.

\section{a. Proses Pemesanan Sepatu}

Melakukan pemesanan dapat dilakukan customer dengan cara mengunjungi website hopeandsoles.id lalu memilih sepatu(produk) yang terdapat di website hopeandsoles.id, lalu website akan menampilkan halaman detil produk. Pada halaman detil produk pelanggan dapat memilih warna sepatu dan ukuran yang ingin dipesan. Lalu pelanggan mengklik tombol add to cart dan pelanggan akan diarahkan ke halaman cart. Pelanggan dapat menambah produk dengan memilih produk yang akan dipesan atau melanjutkan pesanan dengan mengklik tombol checkout. Lalu pelanggan akan diarahkan ke halaman checkout. Pada halaman checkout pelanggan dapat melihat detil pesanan. Setelah itu pelanggan akan mengisi form billing details, yang berisi nama lengkap, email, alamat, provinsi, kota, kode pos, dan catatan. Setelah itu sistem akan menampilkan beberapa perusahaan logistik untuk memilih jenis pengiriman oleh pelanggan. Setelah itu pelanggan akan melakukan pembayaran dengan metode bank transfer. Lalu sistem website akan menampilkan total yang akan dibayar oleh pelanggan dan pelanggan akan mengklik tombol place order. Lalu akan dikirimkan notifikasi oleh sistem website pesanan berhasil dibuat. Proses ini terlihat Pada Gambar 4.

\section{b. Proses Pembayaran}

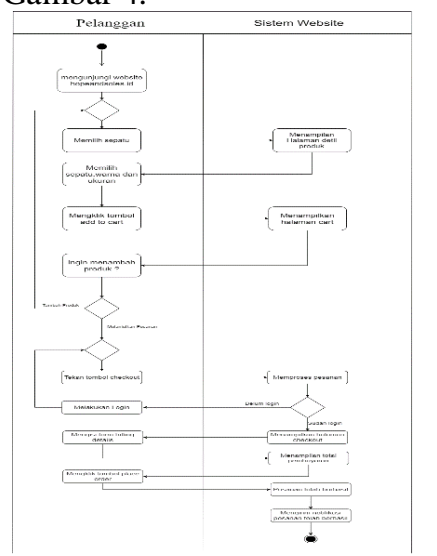

Gambar 4. Proses Pemesanan Sepatu

Pelanggan melakukan pembayaran dengan mengirimkan uang ke rekening hopeandsoles.id dengan jumlah yang sesuai nominal pembayaran agar sistem website dapat memverifikasi pembayaran dengan otomatis. Pembayaran dilakukan dengan metode bank transfer melalui mesin ATM, Mobile Banking, Internet Banking. Setelah sistem website telah memverifikasi pembayaran secara otomatis, lalu sistem akan merubah status pesanan menjadi processing dengan otomatis. Setelah itu sistem website akan mengirimkan notifikasi kepada pelanggan dan admin website. Pelanggan mendapatkan notifikasi bahwa pesanan sedang diproses dan admin website mendapatkan notifikasi pembayaran telah diterima. Proses ini terlihat Pada Gambar 5.

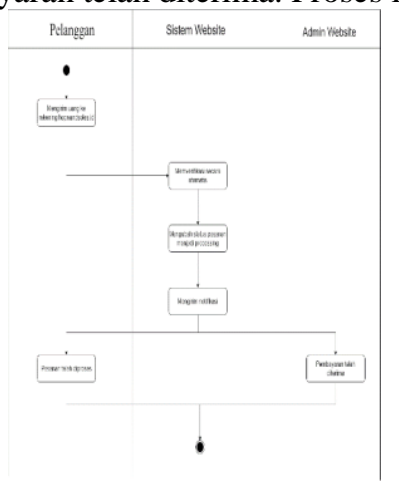

Gambar 5. Proses Pembayaran 


\section{c. Proses Pengiriman}

Pada proses pengiriman sepatu admin website akan membuka halaman back end wordpress, lalu menuju halaman woocommerce, lalu mengklik теnи orders. Pada halaman orders admin akan mencetak label pesanan dengan cara memilih pesanan yang akan dicetak. Pada bagian print shipping label, admin akan menekan tombol print now. Lalu admin akan menyiapkan pesanan dan menunggu pihak perusahaan logistik untuk mengambil pesanan untuk di antar. setelah itu pihak perusahaan logistik akan memberikan resi pengiriman kepada admin untuk dimasukkan nomor resi pengiriman kedalam website. Setelah admin memasukan nomor resi pengiriman sistem website akan mengirimkan notifikasi kepada pelanggan bahwa pesanan telah dikirim dan status pesanan menjadi shipping. Proses ini terlihat Pada Gambar 6.

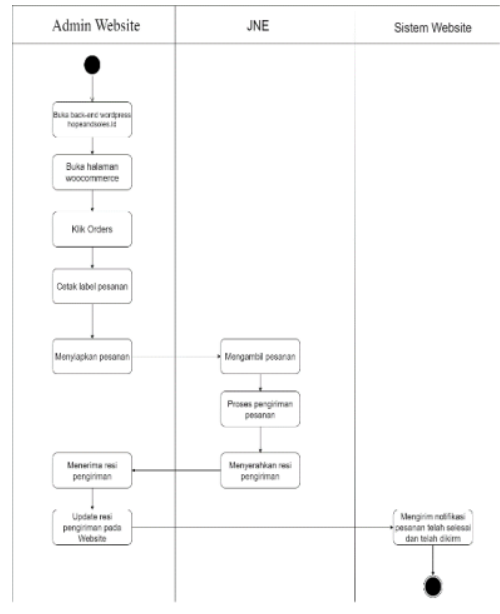

\section{d. Proses Pembuatan Laporan}

Gambar 6. Proses Pengiriman

Setiap akhir bulan admin website akan masuk ke halaman back-end website hopeandsoles.id untuk membuat laporan bulanan yaitu laporan rekapitulasi produk terlaris, pengiriman, pembayaran, pesanan, pendapatan, pendapatan, dan pelanggan. Lalu admin akan menyerahkan laporan tersebut kepada pemilik hopeandsoles.id. Laporan yang dihasilkan, akan membuat informasi laporan menjadi lebih informatif bagi pemilik toko sepatu. Proses pembuatan laporan ini terlihat Pada Gambar 7.

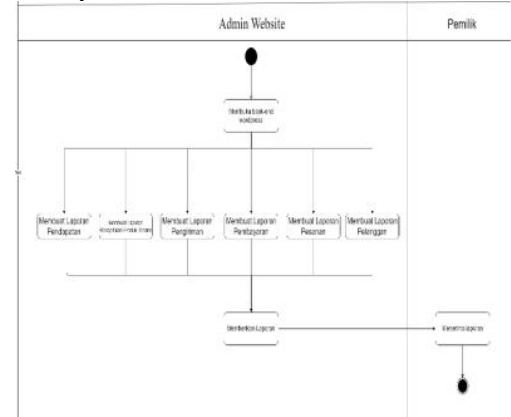

Gambar 7. Proses Pembuatan Laporan

\subsection{Use Case Diagram}

Menurut Nugroho [12] Use Case Diagram merupakan gambaran seluruh actor dan use case untuk menganalisa interaksi yang terjadi dalam suatu sistem. Berikut akan dijelakan use case diagram proses master dan use case diagram proses transaksi pada sistem website ecommerce toko sepatu. Pada Use Case Diagram Master dijelaskan ada aktor yaitu pelanggan dan admin website dan ada 2 kegiatan login dan registrasi dapat dilihat Pada Gambar 8. 


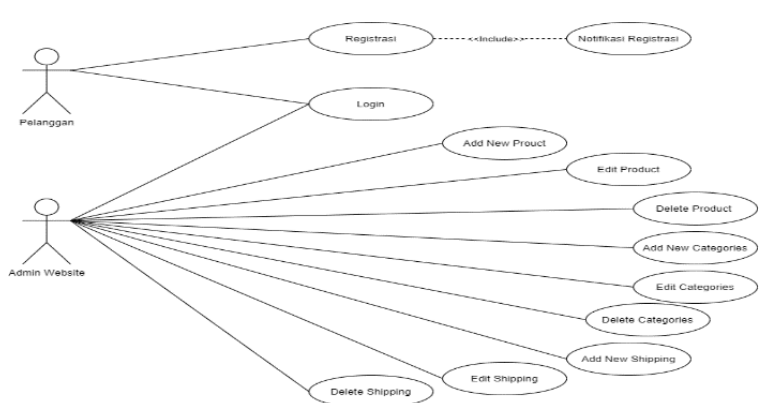

Gambar 8. Use Case Diagram Master

Pada Use Case Diagram Transaksi, terdapat 2 aktor yang menjelaskan use case diagram transaksi. Actor yang dimaksud adalah admin website dan pelanggan. Dan kegiatan yang ada pada proses transaksi, yaitu cetak label pesanan, input no resi, order dan order tracking Pada Gambar 9.

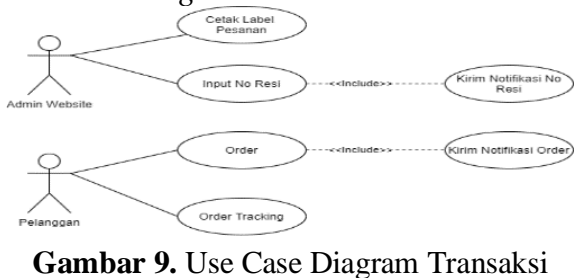

\subsection{Class Diagram}

Gambar 9. Use Case Diagram Transaksi

Menurut Hendini [18] Class Diagram adalah hubungan antar kelas dan penjelasan lengkap pada setiap kelas di dalam model desain dari suatu sistem, juga menujukkan aturann dan tanggung jawab entitas yang menentukan perilaku sistem. Class Diagram untuk membuat sistem ecommerce akan menjadi dasar untuk perancangan basis data yang akan dikoneksikan dengan website e-commerce. Basis data ini akan menyimpan data pelanggan, data penjualan, data pesanan, sehingga semua data saat melakukan transaksi akan terimpan dengan baik dan aman. Class Diagram untuk sistem e-commerce toko sepatu terlihat Pada Gambar 10.

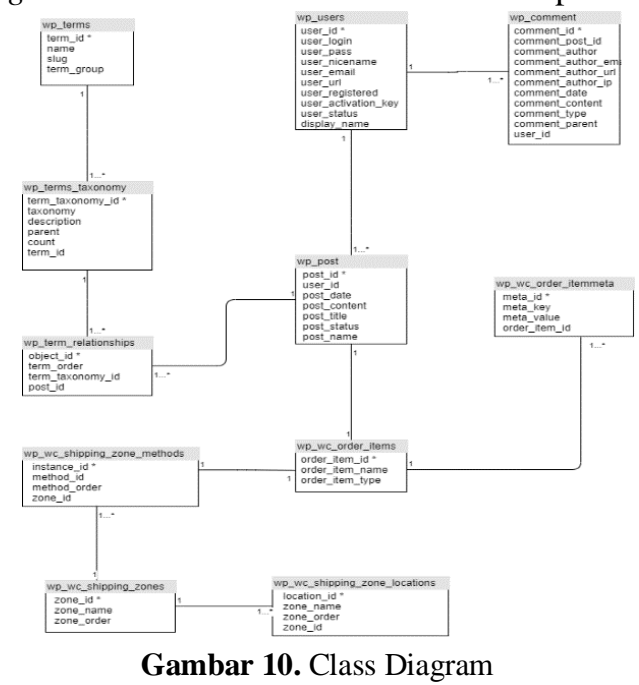

\subsection{Tampilan Layar}

Gambar 10. Class Diagram

Website e-commerce ini diyakini dapat membantu pelanggan lebih mudah bertransaksi secara online. Untuk sistem website e-commerce toko sepatu yang dibuat ini, tampilan layar terbagi menjadi dua, yaitu tampilan layar Front End dan Back End. Berikut adalah penjelasannya untuk tampilan layar Front End dan Back End. a. Tampilan Layar Front end

Pada Gambar 11 menjelaskan tampilan awal dari website, saat pelanggan mengunjungi website toko sepatu. 


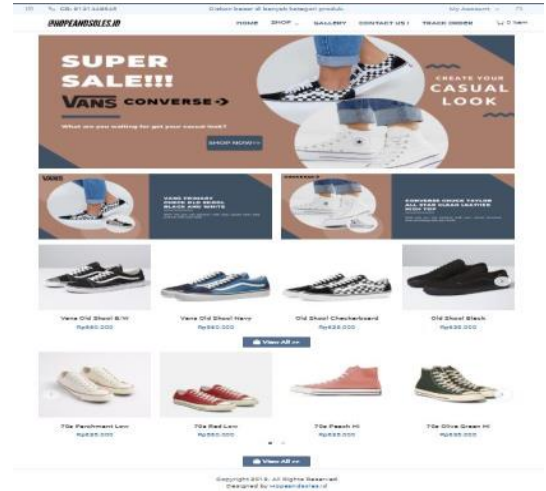

Gambar 11. Tampilan Layar Home

Pada Gambar 12 menjelaskan tampilan page Login ketika pelanggan mengklik menu Login, saat pelanggan melakukan login pada website toko sepatu.

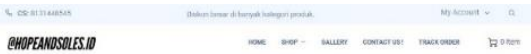

b. Tampilan Layar Back end

enporansolissio

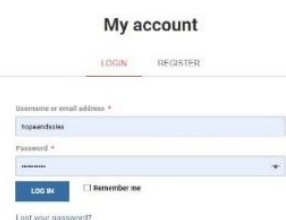

Gambar 12. Tampilan Layar Login

Pada Gambar 13 menjelaskan tampilan dari halaman back-end website toko sepatu untuk menambahkan produk di website E-Commerce toko sepatu.

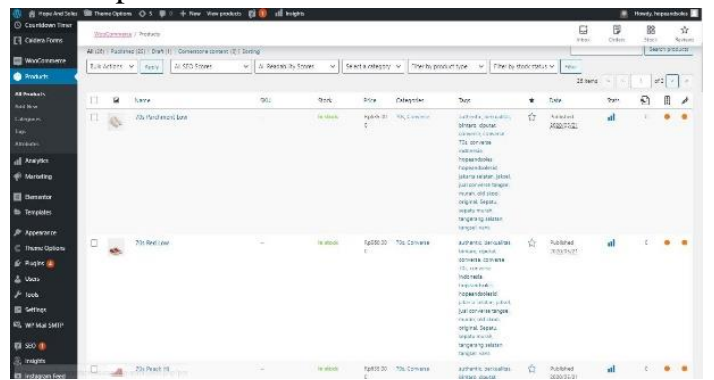

Gambar 13. Tampilan Layar Product Back-End

Pada Gambar 14 menjelaskan tampilan dari halaman back-end website toko sepatu untuk detail order produk di website E-Commerce toko sepatu.

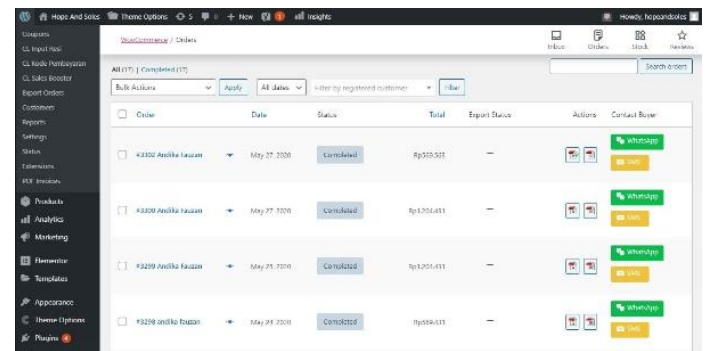

Gambar 14. Tampilan Layar Order Back-End

\subsection{Search Engine Optimaztion}

Dalam strategi Search Engine Optimization (SEO) untuk penerapan e-commerce pada toko sepatu, kami hanya menggunakan strategi SEO On Page. Artanto dan Nurdiyansyah [19] mengemukakan bahwa SEO On Page merupakan sebuah teknik SEO yang difokuskan untuk optimasi pada internal website. Aktifitas On Page ini menyangkut rekayasa terhadap elemen dan isi sebuah website. Penerapan SEO pada suatu website dengan cara 
mengoptimalkan halaman dan konten pada website. Hal ini dilakukan dengan menggunakan plugin Yoast SEO, setelah itu melakukan pengujian indexing pada mesin pencari google. Dengan adanya fitur-fitur yang mendukung untuk melakukan penjualan dan website sudah teroptimasi, maka penjualan akan lebih maksimal dan pemasaran produk lebih efektif.

\subsection{Tahap Pengujian Indexing Pada Mesin Pencari Google}

Setelah melakukan penerapan SEO di website dengan menggunakan plugin Yoast SEO, perlu dilakukan pengujian indexing pada mesin pecari google. Hal ini berguna untuk mengetahui apakah website tersebut sudah terindeks, atau belum terindeks. Pengujian dapat dapat dilakukan dengan cara mengetik site://hopeandsolesid.com/ di pencarian google. Hasil pencarian dengan keyword "jual converse 70s olive green hi di ciputat" tampil pada halaman 1 urutan ke 3 di mesin pencari Google pada tanggal 12 Juni 2020 Pada Gambar 15.

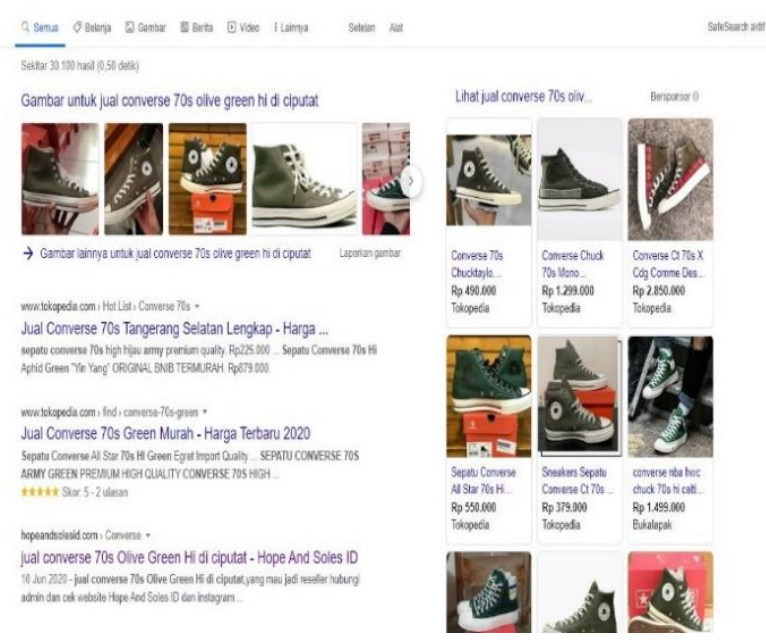

Gambar 15. Hasil Pencarian Dengan Search Engine Google

\section{KESIMPULAN}

Berdasarkan penelitian yang telah dilakukan pada toko sepatu hopeandsoles.id, dapat diambil beberapa poin kesimpulan sebagai berikut:

a. Media pemasaran menjadi lebih efektif dengan adanya website dan didukung oleh teknik SEO pada mesin pencari untuk website, lalu dengan adanya pendataan produk sehingga data dapat diolah kembali untuk melakukan pemasaran produk untuk mendatangkan calon pembeli.

b. Dengan tersedianya beberapa fitur, akan memudahkan pelanggan untuk bertransaksi secara online. Diantaranya adalah informasi tentang produk, foto testimonial dari pelanggan, dan pelanggan pun akan mendapatkan informasi nomor resi pengiriman dan dapat melacak pengiriman pada menu track order, sehingga menambah pelayanan hopeandsoles.id menjadi lebih baik dan informatif.

c. Dengan adanya website E-Commerce pada hopeandsoles.id, pencatatan pesanan tidak dilakukan secara manual, dan tersimpan dengan baik didalam database website sehingga tidak akan terjadi kesalahan dalam mengelola pesanan.

d. Dengan adanya fitur-fitur yang mendukung untuk melakukan penjualan dan website sudah teroptimasi maka penjualan akan lebih maksimal.

e. Pada website hopeandsoles.id menghasilkan lap.rekapitulasi produk terlaris, lap.pengiriman, lap.pembayaran, lap.pesanan, lap.pelanggan, dan lap.pendapatan yang dibutuhkan oleh pemilik toko, sehingga informasi yang dibutuhkan efektif dan informatif.

\section{DAFTAR PUSTAKA}

[1] S. Kosasi, "Pembuatan Sistem Informasi Penjualan Berbasis Web Untuk Memperluas Pangsa Pasar," Pembuatan Sist. Inf. Penjualan Berbas. Web Untuk Memperluas Pangsapasar, pp. 225-232, 2014.

[2] M. F. Hutama and Y. Santoso, "Implementasi E-Commerce Berbasis Content Management System Pada Sepokatsepatu," J. IDEALIS, vol. 3, no. 1, pp. 468-473, 2020.

[3] S. Elinawati, A. Muhammad, and S. Arlis, "Perancangan Content Management System (CMS) Dengan Studi Kasus E-Bisnis Pada 
INDONESIA JOURNAL INFORMATION SYSTEM (IDEALIS)

Volume 4, Nomor 1, Januari 2021

ISSN 2684-7280 (online)

Halaman 20-30

available online at http://jom.fti.budiluhur.ac.id/index.php/IDEALIS/index

Toko Alya Gorden,” J. KomTekInfo Fak. Ilmu Komput., vol. 2, no. 1, pp. 79-90, 2015.

[4] M. Alwiyah and G. Gata, "E-Commerce Untuk Meningkatkan Penjualan Sepatu Sneakers Bintaro," J. IDEALIS, vol. 2, no. 6, pp. 345-350, 2019.

[5] R. R. Rerung, E-Commerce, Menciptakan Daya Saing Melalui Teknologi Informasi. Deepublish, 2018.

[6] E. Turban, J. Outland, D. King, J. K. Lee, T.-P. Liang, and D. C. Turban, Electronic Commerce 2018 : a Managerial and Social Networks Perspective. Springer, 2017.

[7] M. Pradana, “Klasifikasi Jenis-Jenis Bisnis E-Commerce,” J. Neo-bis, vol. 9, no. 2, pp. 32-40, 2015.

[8] V. Vysotska, V. B. Fernandes, and M. Emmerich, "Web Content Support Method in Electronic Business Systems.," in COLINS, 2018, pp. 20-41.

[9] H. Stern, D. Damstra, and B. Williams, Professional WordPress : Design and Development. Indianapolis, Indiana: Wiley Publishing, 2010.

[10] I. Suryono and C. Java, Toko Online Professional Dengan Blogger dan WordPress. Elex Media Komputindo, 2014.

[11] E. Oley, S. R. Sentinuwo, and A. A. E. Sinsuw, "Sistem Pemesanan Makanan Dan Minuman Berbasis Website (Studi Kasus Taipan Restoran)," J. Tek. Elektro dan Komput., vol. 6, no. 4, pp. 159-170, 2017.

[12] A. Nugroho, Rekayasa Perangkat Lunak Menggunakan UML dan JAVA. Yogyakarta: Andi, 2009.

[13] K. Y. P. Dinata and E. Chumaidiyah, "Pengembangan Model Bisnis Pada Serantau Coffee Dengan Menggunakan Pendekatan Business Model Canvas," eProceedings Eng., vol. 6, no. 2, 2019.

[14] A. Osterwalder and Y. Pigneur, "Business model canvas," Self Publ. Last, 2010.

[15] A. Osterwalder and Y. Pigneur, Business model generation: a handbook for visionaries, game changers, and challengers. John Wiley \& Sons, 2010.

[16] D. A. Diartono, Y. Suhari, and A. Supriyanto, "Pengembangan Model CYBER CLUSTER E-COMMERCE Berbasis CMS dan SEO Produk UMKM," IJCCS (Indonesian J. Comput. Cybern. Syst., vol. 9, no. 2, p. 145, 2015, doi: 10.22146/ijccs.7543.

[17] E. Triandini and I. G. Suardika, Step by Step Desain Proyek Menggunakan UML. Penerbit Andi, 2012.

[18] A. Hendini, "Pemodelan UML Sistem Informasi Monitoring Penjualan Dan Stok Barang (Studi Kasus: Distro Zhezha Pontianak)," J. Khatulistiwa Inform., vol. IV, no. 2, pp. 107-116, 2016.

[19] H. Artanto and F. Nurdiyansyah, "Penerapan SEO (Search Engine Optimization) Untuk Meningkatkan Penjualan Produk," JOINTECS (Journal Inf. Technol. Comput. Sci., vol. 2, no. 1, pp. 2-5, 2017, doi: 10.31328/jointecs.v2i1.409. 